http://dx.doi.org/10.32929/2446-8355.2020v29n3p326-336

\title{
DOSES DE NITROGÊNIO EM COBERTURA E INOCULAÇÃO COM Rhizobium tropici NA CULTURA DO FEIJÃO-VAGEM
}

\author{
Karen Andreon Viçosi ${ }^{1 *}$, Adilson Pelá2
}

\footnotetext{
${ }^{1}$ Mestre em Produção Vegetal pela Universidade Estadual de Goiás, Campus Ipameri-GO. *E-mail do autor correspondente: karen_vicosi@hotmail.com

${ }^{2}$ Professor Doutor da Universidade Estadual de Goiás, Campus Ipameri-GO.
}

Recebido: 28/02/20; Aceito: 17/07/2020

RESUMO: O objetivo deste experimento foi avaliar a influência de doses de adubação nitrogenada e da inoculação com Rhizobium tropici na nutrição e nodulação do feijão-vagem. $\mathrm{O}$ experimento foi conduzido no delineamento inteiramente casualizado, com quatro repetições, no esquema fatorial $5 \times 2$ que correspondem, respectivamente, a cinco doses de $\mathrm{N}$ em cobertura $\left(0,30,60,90\right.$ e $\left.120 \mathrm{~kg} \mathrm{ha}^{-1}\right)$ aos 15 dias após a emergência, na ausência e na presença de inoculante rizobiano. Foram avaliados, no estádio de florescimento, a massa seca radicular (MSR), número de nódulos (NN), teor de nitrogênio da parte aérea (TNPA) e eficiência de utilização de nitrogênio (EUN). Todas as variáveis analisadas foram influenciadas somente pela dose de nitrogênio em cobertura, não constatando efeito significativo da inoculação ou da interação entre a dose e a inoculação. $\mathrm{O}$ aumento das doses de nitrogênio reduziu a MSR, NN e EUN, que apresentaram maiores médias na ausência de adubação nitrogenada. A inoculação é afetada negativamente pelo uso de adubo nitrogenado. A ausência de adubação nitrogenada de cobertura favorece a nodulação. A adubação de cobertura com nitrogênio aumenta o teor de nitrogênio da parte aérea em doses de até $40 \mathrm{~kg}$ ha $^{-1}$, porém reduz a massa seca radicular, número de nódulos e eficiência de utilização de nitrogênio.

Palavras-chave: Fixação biológica de nitrogênio. Nodulação. Phaseolus vulgaris L.

\section{NITROGEN DOSES IN COVERAGE AND INOCULATION WITH Rhizobium tropici IN THE SNAP BEAN CULTURE}

\begin{abstract}
The objective of this experiment was to evaluate the influence of nitrogen fertilization and inoculation with Rhizobium tropici on the nutrition and nodulation of the snap bean. The experiment was was carried out in a completely randomized design, with four replications, in the $5 \times 2$ factorial scheme, corresponding to five $\mathrm{N}$ rates in the cover $(0,30,60$, 90 and $120 \mathrm{~kg} \mathrm{ha}^{-1}$ ), respectively, at 15 days after emergence, in the absence and presence of rhizobial inoculant. At the flowering stage, root dry mass (RDM), number of nodules (NN), nitrogen content of aerial part (NCAP) and nitrogen utilization efficiency (NUE) were evaluated. All the analyzed variables were influenced only by the dose of nitrogen in the cover, not finding significant effect of the inoculation or the interaction between the dose and the inoculation. The increase of the nitrogen rates reduced the RDM, NN and NUE, which showed higher averages in the absence of nitrogen fertilization. Inoculation is negatively
\end{abstract}


affected by the use of nitrogen fertilizer. The absence of nitrogenous fertilization of cover favors the nodulation. Nitrogen fertilization increases the nitrogen content of the aerial part, but reduces root dry mass, number of nodules and efficiency of nitrogen utilization.

Key words: Biological fixation of nitrogen. Nodulation. Phaseolus vulgaris L.

\section{INTRODUÇÃO}

O feijão-vagem (Phaseolus vulgaris L.) é uma leguminosa hortícola, de grande importância econômica, na qual são consumidas suas vagens na forma imatura, rica em vitaminas essenciais (A, B12 e C), minerais e fibras, tornando-se uma excelente fonte de nutrientes para consumo humano (FILGUEIRA, 2013).

Assim como outras leguminosas, o feijão-vagem é uma fabácea nodulífera com capacidade de estabelecer simbiose mutualista com bactérias da família Rhizobiacea, presente naturalmente no solo ou por meio de inoculação de sementes, e assim se beneficiar do nitrogênio fixado, em um processo denominado fixação biológica do nitrogênio (FBN) (MATOSO; KUSDRA, 2014). Dentre as diversas bactérias que são capazes de estabelecer simbiose com o feijão-vagem, o Rhizobium tropici é a espécie mais adaptada e recomendada para os solos ácidos tropicais, devido a sua grande capacidade de nodulação e alta tolerância a estresses ambientais, como alta temperatura, acidez e salinidade (CERRO et al., 2017).

A simbiose entre rizóbios e plantas que realizam a FBN é observada para grande parte das leguminosas de importância agrícola, como a soja, amendoim, feijão comum, feijãocaupi, entre outras diversas espécies (FLORENTINO et al., 2018). No entanto, embora a cultura tenha bom potencial para fixação de nitrogênio, é relatado que a espécie tem menor eficiência de FBN em relação as outras leguminosas, sendo que a inoculação com rizóbio pode não proporcionar a quantidade de $\mathrm{N}$ necessária para atingir altos níveis de produtividade (BRITO et al., 2015; CHEKANAI et al. 2018). Uma estratégia seria então realizar a inoculação com rizóbio combinado com a aplicação de pequenas doses de $\mathrm{N}$ mineral, de modo a aumentar a eficiência do processo de FBN.

A fixação biológica do nitrogênio, através da simbiose do feijão-vagem com bactérias fixadoras de $\mathrm{N}$ atmosférico, surge como uma alternativa sustentável em relação ao uso de fertilizantes nitrogenados, sendo uma tecnologia capaz de substituir, parcial ou integralmente, a adubação nitrogenada mineral (KANEKO et al., 2010; FONSECA et al., 2013).

Apesar dos inúmeros benefícios da fixação biológica para as leguminosas, ainda há poucos estudos sobre este processo para o feijão-vagem, o que o torna pouco eficiente no acúmulo de nitrogênio na planta, fazendo com que a cultura seja dependente de fontes nitrogenadas minerais. Tendo-se em vista que a técnica de inoculação com rizóbios, por si só, ainda não é totalmente eficiente para a cultura, é necessário estudar alternativas para aumentar a eficiência da FBN e beneficiar, principalmente, os pequenos agricultores (BERTOLDO et al., 2015).

O objetivo deste experimento foi avaliar a influência das doses de adubação nitrogenada e da inoculação com Rhizobium tropici na nutrição e nodulação do feijão-vagem. 


\section{MATERIAL E MÉTODOS}

O experimento foi realizado em casa de vegetação pertencente a Universidade Estadual de Goiás, Campus Ipameri, situada nas coordenadas geográficas de $17^{\circ} 9^{\prime} 59^{\prime}$ " W e 48 26'34" S, com altitude aproximada de 800 metros. O clima é considerado tipo Aw, caracterizado por clima tropical úmido, com verão chuvoso e inverno seco, segundo classificação de Koppen (ALVARES et al., 2013).

O solo foi coletado na camada arável $(0-0,20 \mathrm{~m})$ de um LATOSOLO VERMELHO Distrófico (SANTOS et al., 2018), o qual foi destorroado, homogeneizado e passado em peneira de $4 \mathrm{~mm}$ e colocado em vaso de nove litros. Previamente à instalação do experimento, o solo apresentava os seguintes parâmetros químicos e físicos: $\mathrm{pH}-\mathrm{CaCl}_{2} 5,1$; argila $300 \mathrm{~g} \mathrm{~kg}^{-}$ 1; Ca, $\mathrm{Mg}$ e Al trocáveis 2,8, 1,8 e $0 \mathrm{mg} \mathrm{dm}^{-3}$, respectivamente (extraídos por $\mathrm{KCl} 1 \mathrm{~mol} \mathrm{~L}^{-1}$ ); $\mathrm{P}$ e $\mathrm{K}$ disponíveis 4,7 e $78 \mathrm{mg} \mathrm{dm}^{-3}$, respectivamente (extraídos por Mehlich ${ }^{-1}$ ), matéria orgânica $28,0 \mathrm{~g} \mathrm{~kg}^{-1}$.

O experimento foi conduzido no delineamento inteiramente casualizado (DIC), com quatro repetições, no esquema fatorial $5 \times 2$ que correspondem, respectivamente, a cinco doses de $\mathrm{N}$ em cobertura $\left(0,30,60,90\right.$ e $\left.120 \mathrm{~kg} \mathrm{ha}^{-1}\right)$ aos 15 dias após a emergência, na ausência e presença de inoculante rizobiano (Rhizobium tropici). Foi utilizada a cultivar Stringless Green, de crescimento determinado.

A adubação de semeadura foi realizada com $50 \mathrm{~kg} \mathrm{ha}^{-1}$ de $\mathrm{N}, 300 \mathrm{~kg} \mathrm{ha}^{-1} \mathrm{de}^{\mathrm{P}_{2} \mathrm{O}_{5}}$ e 100 $\mathrm{kg} \mathrm{ha}^{-1}$ de $\mathrm{K}_{2} \mathrm{O}$, utilizando como fonte superfosfato simples amoniado (03-17-00) e cloreto de potássio $\left(60 \%\right.$ de $\left.\mathrm{K}_{2} \mathrm{O}\right)$. A adubação de cobertura foi realizada 15 dias após a emergência, utilizando ureia (45\% de nitrogênio), conforme as doses de cada tratamento, anteriormente especificadas (TRANI et al., 2015).

O inoculante foi aplicado na forma de fluído líquido contendo 3,0 x $10^{9}$ células viáveis por mL de Rhizobium tropici Semia 4077 e Semia 4088, na dose de $100 \mathrm{~mL}$ para $40 \mathrm{~kg}$ de sementes. A inoculação foi realizada durante a semeadura, sendo misturado diretamente na semente.

O experimento foi conduzido até as plantas atingirem o estádio fenológico $\mathrm{R}_{6}$ (floração) para a realização das análises.

A parte aérea foi retirada para a obtenção da massa seca da parte aérea (MSPA), teor nitrogênio na parte aérea (TNPA) e eficiência utilização do nitrogênio (EUN). As raízes foram cuidadosamente lavadas em água corrente para retirada do solo adjacente a elas para a contagem de número de nódulos (NE) e massa seca da raiz (MSR).

A parte aérea e o sistema radicular foram obtidas após secagem em estufa com circulação forçada de ar a temperatura de $65^{\circ} \mathrm{C}$ até obtenção de massa constante, para posterior pesagem em balança digital.

Para a avaliação do teor nitrogênio na parte aérea (TNPA), foi utilizada a massa seca da parte aérea, que após a pesagem, foram moídas no Macro Moinho de facas tipo Willey, com peneira de 30 mesh. Em seguida, determinado o teor de nitrogênio conforme método Kjeldahl, que consiste na digestão sulfúrica+destilação+titulação, conforme metodologia 
descrita em Carmo et al. (2000).

Posteriormente, foi calculada a eficiência de utilização do nitrogênio (EUN) por meio da Equação 1:

$$
\text { EUN }=\text { MSPA/NAPA }
$$

em que: $M S P A=$ massa seca da parte aérea, em g; $N A P A=$ nitrogênio acumulado na parte aérea amostras, em $\mathrm{g}$.

Os dados foram submetidos à análise de variância, e quando significativos, as médias foram comparada pelo teste de Scott-Knott a 5\% de probabilidade, e posteriormente calculada a análise de regressão com maior coeficiente de correlação significativo para as doses estudadas.

\section{RESULTADOS E DISCUSSÃO}

Na Tabela 1 estão apresentados os valores de F, análise de regressão e os valores médios observados para as variáveis analisadas. A massa seca radicular, número de nódulos, teor de nitrogênio da parte aérea e a eficiência de utilização de nitrogênio foram influenciados somente pela dose de nitrogênio em cobertura, não constatando efeito significativo da inoculação ou da interação entre a dose e a inoculação.

Tabela 1. ANAVA, análise de regressão e teste de médias da massa seca radicular (MSR), número de nódulos $(\mathrm{NN})$, teor de nitrogênio da parte aérea (TNPA) e eficiência de utilização de nitrogênio (EUN) em cobertura, na ausência e presença de inoculação com $R$. tropici. ANOVA, regression analysis and averages test of root dry mass (RDM), number of nodules $(N N)$, nitrogen content of aerial part (NCAP) and nitrogen utilization efficiency (NUE) in coverage, in different nitrogen rates in coverage, in the absence and presence of inoculation with R. tropici.

\begin{tabular}{|c|c|c|c|c|}
\hline Análise & MSR & $\mathbf{N N}$ & TNPA & EUN \\
\hline \multicolumn{5}{|l|}{ ANAVA } \\
\hline Dose & $3,318^{\text {** }}$ & $8,646^{*}$ & $10,472 *$ & $4,664 *$ \\
\hline Inóculo & 0,042 & 0,919 & 0,689 & 0,467 \\
\hline$I \times D$ & 0,200 & 0,158 & 0,901 & 0,323 \\
\hline \multicolumn{5}{|l|}{ REGRESSÃO } \\
\hline I. Ausente & 0,111 & $0,020 * *$ & $0,012^{* *}$ & $0,017 * *$ \\
\hline I. Presente & 0,212 & $0,022 * *$ & $0,025^{* *}$ & $0,041 * *$ \\
\hline \multicolumn{5}{|c|}{ DOSE $\left(\mathrm{kg} \mathrm{ha}^{-1}\right)$} \\
\hline 0 & $0,86 \mathrm{a}$ & $13,25 \mathrm{a}$ & $30,8 \mathrm{~b}$ & $0,097 \mathrm{a}$ \\
\hline 15 & $0,44 \mathrm{~b}$ & $2,12 \mathrm{~b}$ & 39,7 a & $0,053 \mathrm{~b}$ \\
\hline 30 & $0,58 \mathrm{~b}$ & $0,50 \mathrm{~b}$ & $41,1 \mathrm{a}$ & $0,052 \mathrm{~b}$ \\
\hline 45 & $0,45 \mathrm{~b}$ & $0,75 \mathrm{~b}$ & $41,5 \mathrm{a}$ & $0,044 \mathrm{~b}$ \\
\hline 60 & $0,54 \mathrm{~b}$ & $0,87 \mathrm{~b}$ & $40,9 \mathrm{a}$ & $0,061 \mathrm{~b}$ \\
\hline \multicolumn{5}{|c|}{ INOCULAÇÃO } \\
\hline Ausente & 0,57 & 2,70 & 39,3 & 0,058 \\
\hline Presente & 0,58 & 4,30 & 38,3 & 0,064 \\
\hline
\end{tabular}

Nota: Médias seguidas pela mesma letra pertencem a um mesmo grupo de acordo com o teste Scott-Knott (p>0,05). *Significativo a $5 \%$ de probabilidade. ** Significativo a $1 \%$ de probabilidade. Means followed by the same letter belong to the same agreement group with the Scott-Knott test $(p>0.05)$. * Significant at 5\% probability. ** Significant at $1 \%$ probability.

Fonte: Autoria própria. Own authorship. 
As doses de nitrogênio diferiram entre si para todas as variáveis, sendo que a dose de 0 $\mathrm{kg} \mathrm{ha}^{-1}$ (ausência de adubação) apresentou média superior para a MSR, NN e EUN, e inferior para o TNPA. Em relação à análise de regressão em função das doses, foi significativa apenas para o NN, TNPA e EUN. Observa-se ainda que não houve efeito do inoculante na presença da adubação nitrogenada, constatado pela não diferença entre as médias das plantas inoculadas e não inoculadas.

O número de nódulos apresentou comportamento quadrático em função das doses de adubação nitrogenada em cobertura (Figura 1). A dose de $0 \mathrm{~kg} \mathrm{ha}^{-1}$ proporcionou maiores valores de nodulação, com a nodulação sendo nula nas doses de 40,6 $\mathrm{kg} \mathrm{ha}^{-1}$ e 45,33 kg ha-1 para as plantas inoculadas e não inoculadas, respectivamente.

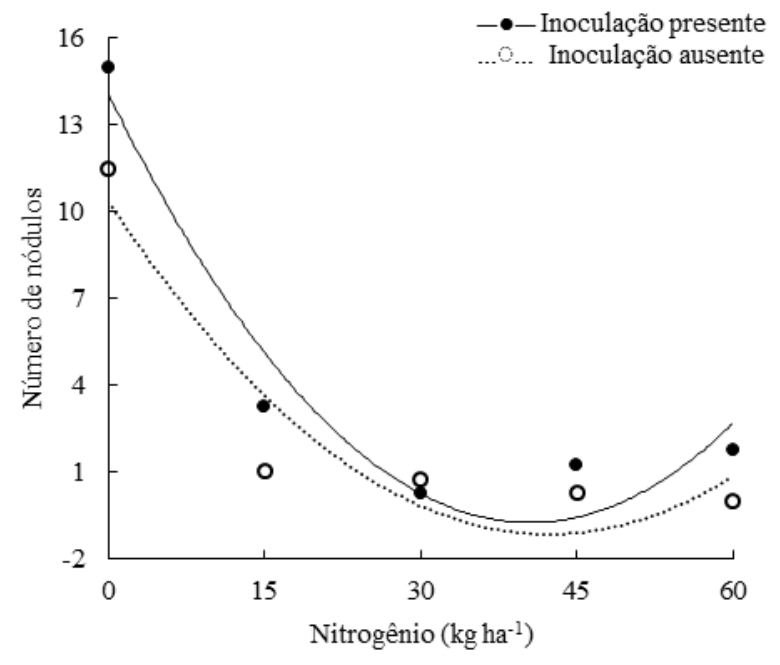

Nota: Inoculação presente: $y=14,071-0,7329 x+0,009 x 2 ; R^{2}=0,9421^{*}$. Inoculação ausente: $y=10,343-$ $0,544 \mathrm{x}+0,0064 \mathrm{x}^{2} ; \mathrm{R}^{2}=0,8796 *$ * Significativo a $5 \%$ de probabilidade. Present inoculation: $y=14.071-$ $0.7329 x+0.009 x 2 ; R^{2}=0.9421^{*}$. Absent inoculation: $y=10.343-0.544 x+0.0064 x^{2} ; R^{2}=0.8796^{*}$. *Significant at $5 \%$ probability.

Figura 1. Número de nódulos em função da dose de nitrogênio em cobertura, na presença e ausência de inoculação com $R$. tropici. Number of nodules as a function of nitrogen coverage dose, in the presence and absence of inoculation with $R$. tropici.

Fonte: Autoria própria. Own authorship.

O teor de nitrogênio da parte área do feijão-vagem apresentou comportamento quadrático, com os maiores acúmulos nas doses de 44,17 e 43,33 $\mathrm{kg} \mathrm{ha}^{-1}$ para os tratamentos inoculados e não inoculados, respectivamente (Figura 2). Todos os tratamentos apresentaram teor de nitrogênio adequado para a planta, sendo que a faixa ideal situa-se entre 30 a $50 \mathrm{~g} \mathrm{~kg}^{-1}$, entretanto, a ausência de adubação nitrogenada obteve menor TNPA.

Para a eficiência de utilização do nitrogênio, o comportamento quadrático repetiu-se, sendo que aumento da dose de nitrogênio reduziu a eficiência do nutriente, quadrático com o mínimo de eficiência na dose de 35, para plantas inoculadas e $34,6 \mathrm{~kg} \mathrm{ha}^{-1}$, para não inoculadas, conforme Figura 3. Novamente, a dose de $0 \mathrm{~kg} \mathrm{ha}^{-1}$ mostrou-se superior, apresentando a maior EUN. 


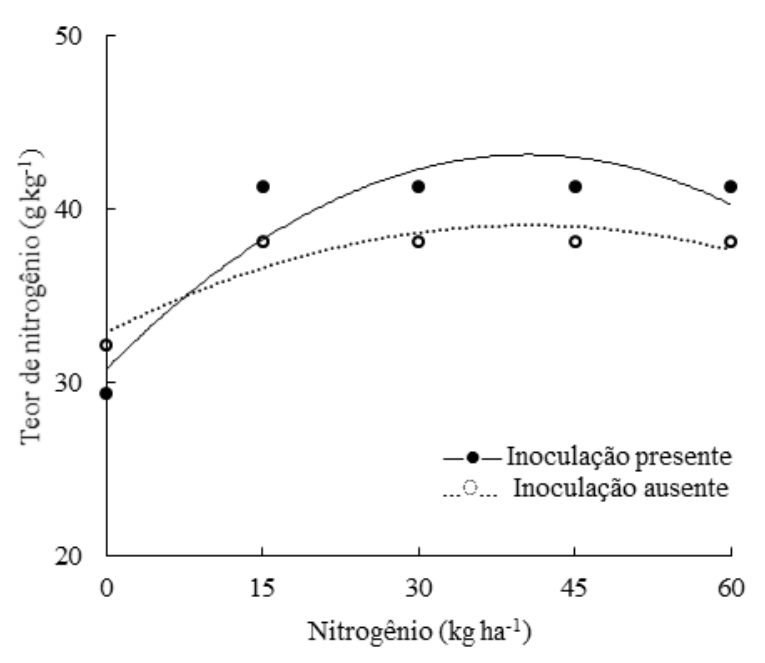

Nota: Inoculação presente: $\mathrm{y}=30,76+0,612 \mathrm{x}-0,0076 \mathrm{x} 2 ; \mathrm{R}^{2}=0,8571 *$. Inoculação ausente: $\mathrm{y}=32,88+0,306 \mathrm{x}$ - $0,0038 \mathrm{x}^{2} ; \mathrm{R}^{2}=0,857 *$. Significativo a $5 \%$ de probabilidade. Present inoculation: $y=30.76+0.612 x-$ $0.0076 x 2 ; R^{2}=0.8571 *$ Absent inoculation: $y=32.88+0.306 x-0.0038 x^{2} ; R^{2}=0.857 *$ * Significant at $5 \%$ probability.

Figura 2. Teor de nitrogênio da parte aérea em função da dose de nitrogênio em cobertura, na presença e ausência de inoculação com $R$. tropici. Nitrogen content of aerial part as a function of nitrogen coverage dose, in the presence and absence of inoculation with $R$. tropici.

Fonte: Autoria própria. Own authorship.

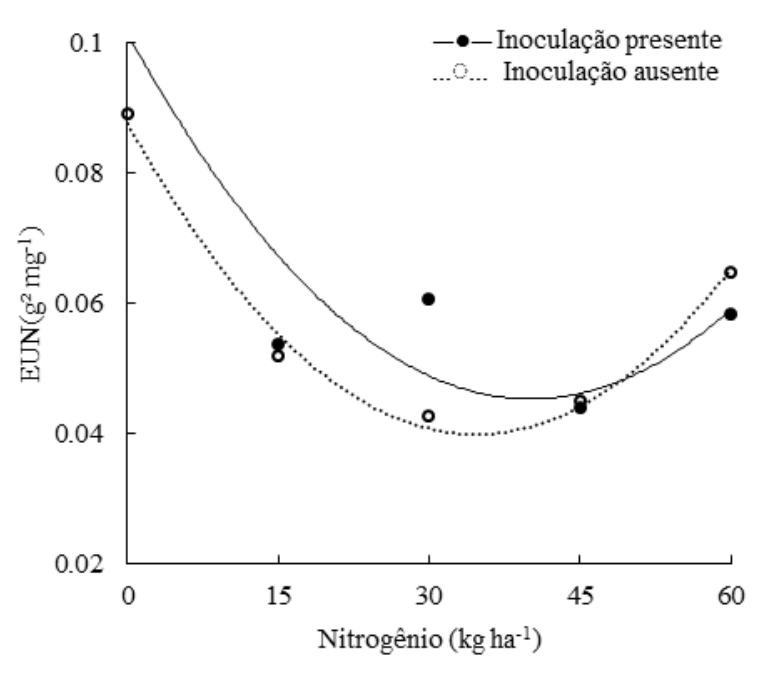

Nota: Inoculação presente: $\mathrm{y}=0,1016-0,0028 \mathrm{x}+0,00004 \mathrm{x} 2 ; \mathrm{R}^{2}=0,848^{*}$. Inoculação ausente: $\mathrm{y}=0,0877$ $0,0028 \mathrm{x}+0,0004 \mathrm{x}^{2} ; \mathrm{R}^{2}=0,9871 *$. Significativo a $5 \%$ de probabilidade. Present inoculation: $y=0.1016-$ $0.0028 x+0.00004 x 2 ; R^{2}=0.848 *$. Absent inoculation: $y=0.0877-0.0028 x+0.0004 x^{2} ; R^{2}=0.9871 *$ * Significant at $5 \%$ probability.

Figura 3. Eficiência de utilização do nitrogênio (EUN) em função da dose de nitrogênio em cobertura, na presença e ausência de inoculação com $R$. tropici. Efficiency of nitrogen utilization (ENU) as a function of nitrogen coverage dose, in the presence and absence of inoculation with $R$. tropici.

Fonte: Autoria própria. Own authorship.

A adubação nitrogenada de cobertura mostra um efeito deletério em relação a fixação 
biológica de nitrogênio, sendo capaz de reduzir a nodulação tanto na presença quanto na ausência de inoculante, demostrando que não há desenvolvimento da bactéria na presença da ureia. Diversos estudos confirmam o efeito negativo do adubo nitrogenado na nodulação, no qual foi observado que mesmo as aplicações de baixas quantidades do nutriente são capazes de inibir a nodulação em feijoeiro. Martins et al. (2013) verificaram respostas lineares decrescentes em função do aumento da adubação nitrogenada, evidenciando, assim, o papel inibidor do N-mineral sobre a nodulação de feijão-caupi, enquanto que Silva et al. (2012) concluíram que aplicação de $\mathrm{N}$ equivalente a $20 \mathrm{~kg} \mathrm{ha}^{-1}$ inibiu a nodulação espontânea em plantas de feijão-caupi, em casa de vegetação. Zuffo et al. (2019) afirmaram que a adubação nitrogenada na cultura da soja é capaz de inibir a nodulação, através da redução do número de nódulos, volume dos nódulos e matéria seca dos nódulos, corroborando com o presente trabalho.

Brito et al. (2011) concluíram que o incremento na dose de nitrogênio proporciona redução na fixação simbiótica de nitrogênio nas plantas de feijão comum e de caupi, demonstrando que o aumento na concentração de $\mathrm{N}$ mineral na solução do solo desfavorece o processo de simbiose entre a planta e o rizóbio. Esse aumento da concentração do nitrogênio na solução do solo é devido a presença do nitrato e o nitrito, que acumulados a nível nodular são capazes de inibir a FBN devido a diminuição da disponibilidade de energia ao bacteroide. Mendes et al. (2008) descreveram que sempre que a disponibilidade de $\mathrm{N}$ no solo é abundante, este é absorvido em detrimento ao $\mathrm{N}$ da FBN, enquanto o $\mathrm{N}$-fixado é a maior fonte do nutriente absorvido somente quando o $\mathrm{N}$ do solo torna-se limitante, o que explica os resultados encontrados.

A única variável que se beneficiou com a adubação de cobertura foi o teor de nitrogênio da parte aérea. Resultado de TNPA semelhante foi encontrado por Florentino et al. (2018), em que o TNPA foi diretamente relacionado à aplicação de $\mathrm{N}$ mineral, sendo que a presença de adubação promoveu maior aumento do conteúdo de nitrogênio pela planta, sem notar efeito significativo do inoculante. Kaneko et al. (2010) concluíram que a adubação nitrogenada em cobertura proporciona incrementos quadráticos no teor de $\mathrm{N}$ nas folhas do feijoeiro de inverno, enquanto que Albuquerque et al. (2012) concluíram que a dose de $42 \mathrm{~kg} \mathrm{ha}^{-1}$ de nitrogênio promoveu o maior aumento no teor de nitrogênio foliar, massa seca e produtividade do feijoeiro comum. Esse resultado é semelhante ao encontrado no atual estudo, no qual doses de aproximadamente $40 \mathrm{~kg} \mathrm{ha}^{-1}$, tanto para plantas inoculadas e não inoculadas, apresentaram maior teor de $\mathrm{N}$.

Em relação à eficiência de utilização do nitrogênio, resultado de EUN foi semelhante ao encontrado por Sant'Ana et al. (2011), na qual a eficiência de uso de nitrogênio pelo feijoeiro variou com as doses de nitrogênio, com redução da eficiência com o incremento da dose do adubo. Geralmente, os aproveitamentos de $\mathrm{N}$ decrescem com o aumento das doses aplicadas, em vista de o suprimento de $\mathrm{N}$ exceder as necessidades da cultura; tais decréscimos têm como consequências as perdas de amônia, que aumentam com a dose aplicada, podendo ser de forma linear, quadrática ou exponencial (FERNANDES et al., 2005). Além disso, a eficiência pode ser afetada pela lei dos incrementos decrescentes, no qual a resposta à adubação nas doses mais baixas tende a ser mais expressiva que o aumento obtido com mudanças em doses elevadas, devido a saturação dos sistemas enzimáticos e a possível limitação causada pela 
deficiência de outros nutrientes (MARTUSCELLO et al., 2018). Este fato corrobora com o encontrado neste estudo, no qual para ambos os tratamentos a maior EUN encontra-se na ausência de adubação nitrogenada de cobertura.

Nota-se então que a ausência de adubação de cobertura, quando não foi superior, foi capaz de se igualar ao tratamento com adubação, o que evidencia a capacidade de fornecimento de $\mathrm{N}$ pela inoculação com rizóbios, nativos ou comerciais, ser comparável ao do adubo nitrogenado, mas com a vantagem de ter menor custo de produção e menor impacto ambiental (BARROS et al., 2013).

Apesar de não ter sido observado o efeito da inoculação dos rizóbios, fica evidenciado que a fixação biológica de nitrogênio pode suplementar, ou mesmo substituir, a adubação nitrogenada na cultura do feijão, permitindo redução nas doses de adubo nitrogenado sem ocasionar redução no rendimento de grãos (FERREIRA et al., 2009). Tristão et al. (2019) recomendam a inoculação de sementes de feijoeiro com $R$. tropici, de modo a reduzir a necessidade da adubação nitrogenada em cobertura no feijoeiro

De acordo com Florentino et al. (2018), a inoculação consiste numa prática viável quando não se utilizam fertilizantes nitrogenados na cultura do feijoeiro, contribuindo assim para a redução dos custos de produção e para a sustentabilidade dos agroecossistemas. Contudo, a inoculação ainda é uma escolha sustentável em relação ao uso de fertilizantes nitrogenados inorgânicos, sendo uma alternativa viável e potencialmente menos dispendiosa para melhorar o rendimento das vagens de feijão-vagem (BESHIR et al., 2015).

Diversos trabalhos demonstram que a inoculação, devido ao seu baixo custo do produto e a redução do uso de adubos nitrogenados, é capaz de aumentar a lucratividade da cultura para o produtor rural. Os resultados obtidos por Soares et al. (2016) mostraram que a inoculação combinada com a aplicação de pequenas doses de $\mathrm{N}$ pode contribuir para uma maior lucratividade nos cultivos de feijão, porém deve ser analisada a melhor dose para cada local e tipo de solo, enquanto que Bertoldo et al. (2015) demonstraram que o maior retorno do investimento foi obtido com a inoculação, sendo recomendada para os agricultores que têm poucos recursos para investimento.

\section{CONCLUSÃO}

A inoculação é afetada negativamente pelo uso de adubo nitrogenado.

A ausência de adubação nitrogenada de cobertura favorece a nodulação do feijãovagem.

A adubação de cobertura com dose de $40 \mathrm{~kg} \mathrm{ha}^{-1}$ nitrogênio é capaz de aumentar o teor de nitrogênio da parte aérea, porém reduz a massa seca radicular, número de nódulos e eficiência de utilização de nitrogênio.

\section{AGRADECIMENTOS}

À Universidade Estadual de Goiás, pelo financiamento da pesquisa. 


\section{REFERÊNCIAS BIBLIOGRÁFICAS}

ALBUQUERQUE, H. C.; PEGORARO, R. F.; VIEIRA, N. M. B.; AMORIM, I. J. F.; KONDO, M. K. Capacidade nodulatória e características agronômicas de feijoeiros comuns submetidos à adubação molíbdica parcelada e nitrogenada. Revista Ciência Agronômica, Fortaleza, v. 43, n. 2, p.214-221, 2012. Disponível em: http://dx.doi.org/10.1590/S180666902012000200002. Acesso em: 27 fev. 2020.

ALVARES, C. A.; STAPE, J. L.; SENTElHAS, P. C.; GONCALVES, J. L. de M.; SPAROVEK, G. Köppen's climate classification map for Brazil. Meteorologische Zeitschrift, Stuttgart, v. 22, n. 6, p.711-728, 2013. Disponível em: https://doi.org/10.1127/0941-2948/2013/0507. Acesso em: 12 fev. 2020.

BARROS, R. L. N.; OLIVEIRA, L. B.; MAGALHÃES, W. B.; MÉDICI, L. O.; PIMENTEL, C. Interação entre inoculação com rizóbio e adubação nitrogenada de plantio na produtividade do feijoeiro nas épocas da seca e das águas. Semina: Ciências Agrárias, Londrina, v. 34, n. 4, p.1443-1450, 2013. Disponível em: http://dx.doi.org/10.5433/1679-0359.2013v34n4p1443. Acesso em: 28 jan. 2020.

BERTOldO, J. G.; PEliSSER, A.; SIlVA, R. P.; FAVRETO, R.; OlIVEIRA, L. A. D. Alternativas na fertilização de feijão visando a reduzir a aplicação de N-ureia. Pesquisa Agropecuária Tropical, Goiânia, v.45, n.3, p.348-355, 2015. Disponível em: http://dx.doi.org/10.1590/1983-40632015v4534885. Acesso em: 12 fev. 2020.

BESHIR, H. M.; WALLEY, F. L.; BUECKERT, R.; TAR'AN, B. Response of snap bean cultivars to Rhizobium inoculation under dryland agriculture in Ethiopia. Agronomy, Basel, v. 5, n. 3, p.291-308, 2015. Disponível em: http://dx.doi.org/10.3390/agronomy5030291. Acesso em: 19 ago. 2019.

BRITO, L. F.; PACHECO, R. S.; SOUZA FILHO, B. F.; FERREIRA, E. P. B.; STRALIOTTO, R.; ARAÚJO, A. P. Resposta do feijoeiro comum à inoculação com rizóbio e suplementação com nitrogênio mineral em dois biomas brasileiros. Revista Brasileira de Ciência do Solo, Viçosa, v. 39, n. 1, p.1-12, 2015. Disponível em: http://dx.doi.org/10.1590/01000683rbcs20140322. Acesso em: 27 fev. 2020.

BRITO, M. M. P.; MURAOKA, T.; SILVA, E. C. Contribuição da fixação biológica de nitrogênio, fertilizante nitrogenado e nitrogênio do solo no desenvolvimento de feijão e caupi. Bragantia, Campinas v. 70, n. 1, p.206-215, 2011. Disponível em: http://dx.doi.org/10.1590/S0006-87052011000100027. Acesso em: 12 fev. 2020.

CARMO, C. A. F. S.; ARAÚJO, W. S.; BERnARDI, A. C. C.; SAldANA, M. F. C. Métodos de Análise de Tecidos Vegetais Utilizados na Embrapa Solos. Rio de Janeiro: Embrapa Solos, 2000. 41 p. (Circular Técnica n. 6)

CERRO, P. del; PÉREZ-MONTAÑO, F.; GIL-SERRANO, A.; LÓPEZ-BAENA, F. J.; MEGÍAS, M.; HUNGRIA, M.; OLLERO, F. J. The Rhizobium tropici CIAT 899 NodD2 protein regulates the production of Nod factors under salt stress in a flavonoid independente manner. Nature, London, v. 7, n. 46712, p.1-10, 2017. Disponível em: https://doi.org/10.1038/srep46712. Acesso em: 28 jan. 2020. 
CHEKANAI, V.; CHIKOWO, R.; VANLAUWE, B. Response of common bean (Phaseolus vulgaris L.) to nitrogen, phosphorus and rhizobia inoculation across variable soils in Zimbabwe. Agriculture, Ecosystems and Environment, Enschede, v. 266, p.167-173, 2018. Disponível em: https://doi.org/10.1016/j.agee.2018.08.010. Acesso em: 28 jan. 2020.

FERNANDES, F. C. S.; BUZETTI, S.; ARF, O.; ANDRADE, J. A. C. Doses, eficiência e uso de nitrogênio por seis cultivares de milho. Revista Brasileira de Milho e Sorgo, Sete Lagoas, v. 4, n. 2, p.195-204, 2005. Disponível em: http://dx.doi.org/10.18512/19806477/rbms.v4n02p\%25p. Acesso em: 19 ago. 2019.

FERREIRA, P. A. A.; SILVA, M. A. P.; CASSETARI, A.; RUFINI, M.; MOREIRA, F. M. S.; ANDRADE, M. J. B. Inoculação com cepas de rizóbio na cultura do feijoeiro. Ciência Rural, Santa Maria, v. 39, n. 7, p.2210-2212, 2009. Disponível em: http://dx.doi.org/10.1590/S0103-84782009000700041. Acesso em: 27 fev. 2020.

FILGUEIRA, F. A. R. Novo manual de olericultura: agrotecnologia moderna na produção e comercialização de hortaliças. 3. ed. Viçosa: UFV, 2013. 421 p.

FLORENTINO, L. A.; FRANCO JUNIOR, S.; PAREDES FILHO, M. V.; OLIVEIRA, T. E.; SOUZA, F. R. C.; SILVA, A. B. Inoculação e aplicação de diferentes doses de nitrogénio na cultura do feijoeiro. Revista de Ciências Agrárias, Lisboa, v. 41, n. 4, p.91-100, 2018. Disponível em: http://dx.doi.org/10.19084/RCA17001. Acesso em: 28 jan. 2020.

FONSECA, G. G.; OLIVEIRA, D. P.; SOARES, B. L.; FERREIRA, P. A. A.; TEIXEIRA, C. M.; MARTINS, F. A. D.; MOREIRA, F. M. S.; ANDRADE, M. J. Resposta de cultivares de feijoeiro-comum à inoculação das sementes com duas estirpes de rizóbio. Bioscience Journal, Uberlândia, v. 29, n. 6, p.1778-1787, 2013. Disponível em: http://www.seer.ufu.br/index.php/biosciencejournal/article/view/21870/13415. Acesso em: 19 ago. 2019.

KANEKO, F. H.; ARF, O.; GITTI, D. C.; ARF, M. V.; FERREIRA, J. P.; BUZETTI, S. Mecanismos de abertura de sulcos, inoculação e adubação nitrogenada em Feijoeiro em sistema plantio direto. Bragantia, Campinas, v. 69, n. 1, p.125-133, 2010. Disponível em: http://dx.doi.org/10.1590/S0006-87052010000100017. Acesso em: 03 nov. 2019.

MARTINS, R. N. L.; NÓBREGA, R. S. A.; SILVA, A. F. T.; NÓBREGA, J. C. A.; AMARAL, F. H. C.; COSTA, E. M.; LUSTOSA FILHO, J. F.; MARTINS, L. V. Nitrogênio e micronutrientes na produção de grãos de feijão-caupi inoculado. Semina: Ciências Agrárias, Londrina, v. 34, n. 4, p.1577-1586, 2013. Disponível em: http://dx.doi.org/10.5433/16790359.2013v34n4p1577. Acesso em: 23 dez. 2019.

MARTUSCELlO, J.; RIBEIRO, Y.; BRAZ, T.; FERREIRA, M.; ASSIS, J.; JANK, L.; REIS, G. Produção de forragem, morfogênese e eficiência agronômica do adubo em capim BRS Quênia sob doses de nitrogênio. Boletim de Indústria Animal, Nova Odessa, v. 75, n. 1, p.1-12, 2018. Disponível em: https://doi.org/10.17523/bia.2018.v75.e1411. Acesso em: 03 nov. 2019.

MATOSO, S. C. G.; KUSDRA, J. F. Nodulação e crescimento do feijoeiro em resposta à aplicação de molibdênio e inoculante rizobiano. Revista Brasileira de Engenharia Agrícola 
e Ambiental, Campina Grande, v. 18, n. 6, p.567-573, 2014. Disponível em: http://dx.doi.org/10.1590/S1415-43662014000600001. Acesso em: 28 jan. 2020.

MENDES, I. C.; REIS JUNIOR, F. B.; HUNGRIA, M.; SOUSA, D. M. G.; CAMPO, R. J. Adubação nitrogenada suplementar tardia em soja cultivada em latossolos do Cerrado. Pesquisa Agropecuária Brasileira, Brasília, v. 43, n. 8, p.1053-1060, 2008. Disponível em: http://dx.doi.org/10.1590/S0100-204X2008000800015. Acesso em: 28 jan. 2020.

SANT'ANA, E. V. P.; SANTOS, A. B.; SILVEIRA, P. M. Eficiência de uso de nitrogênio em cobertura pelo feijoeiro irrigado. Revista Brasileira de Engenharia Agrícola e Ambiental, Campina Grande, v. 15, n. 5, p.458-462, 2011. Disponível em: http://dx.doi.org/10.1590/S1415-43662011000500004. Acesso em: 27 fev. 2020.

SANTOS, H. G.; JACOMINE, P. K. T.; ANJOS, L. H. C.; OLIVEIRA, V. A.; LUMRERAS, J. F.; COELHO, M. R.; ALMEIDA, J. A.; ARAUJO FILHO, J. C.; OLIVEIRA, J. B.; CUNHA, T. J. F. Sistema brasileiro de classificação de solos. 5. ed. Brasília: Embrapa, 2018. $590 \mathrm{p}$.

SILVA, M. F.; SANTOS, C. E. R. S.; SOUSA, C. A.; ARAÚJO, R. S. L.; STAMFORD, N. P.; FIGUEIREDO, M. V. B. Nodulação e eficiência da fixação do $\mathrm{N}_{2}$ em feijão-caupi por efeito da taxa do inóculo. Revista Brasileira de Ciência do Solo, Viçosa, v. 36, n. 5, p. 14181425, 2012. Disponível em: http://dx.doi.org/10.1590/S0100-06832012000500005. Acesso em: 23 dez. 2019.

SOARES, B. L.; FERREIRA, P. A. A.; RUFINI, M.; MARTINS, F. A. D.; OLIVEIRA, D. P.; REIS, R. P.; ANDRADE, M. J. B.; MOREIRA, F. M. S. Agronomic and economic efficiency of common-bean inoculation with rhizobia and mineral nitrogen fertilization. Revista Brasileira de Ciência do Solo, Viçosa, v. 40, e0150235, p.1-13, 2016. Disponível em: http://dx.doi.org/10.1590/18069657rbcs20150235. Acesso em: 03 nov. 2019.

TRANI, P. E.; PASSOS, F. A.; PEREIRA, J. E.; SEMIS, J. B. Calagem e adubação do feijão-vagem, feijão-fava (ou fava-italiana), feijão-de-lima e ervilha torta (ou ervilha-devagem). Campinas: IAC, 2015. $15 \mathrm{p}$.

TRISTÃO, F. H. L.; ASSIS, M. W. D.; MINGOTTE, F. L. C.; CALOR, P. S.; SOUZA, J. R.; MORELLO, O. F.; LEMOS, L. B. Inoculação com Rhizobium tropici associada à adubação nitrogenada em cobertura no desempenho agronômico do feijoeiro de inverno. Science and Technology Innovation in Agronomy, Bebedouro, v. 3, n. 1, p.191-201, 2019.

ZUFFO, A. M.; STEINER, F.; BUSCH A.; SANTOS, D. M. S. Adubação nitrogenada na soja inibe a nodulação e não melhora o crescimento inicial das plantas. Revista em Agronegócio e Meio Ambiente, Maringá, v. 12, n. 2, p.333-349, 2019. Disponível em: https://doi.org/10.17765/2176-9168.2019v12n2p333-349. Acesso em: 27 fev. 2020. 